\title{
Publisher Correction: Reflections and projections on a decade of climate science
}

Veronika Eyring (1), Vimal Mishra (D), Gary P. Griffith (1D, Lei Chen (D), Trevor Keenan (D), Merritt R. Turetsky (D), Sally Brown (1D, Frank Jotzo (D), Frances C. Moore and Sander van der Linden (1)

Correction to: Nature Climate Change https://doi.org/10.1038/s41558-021-01020-x, published online 1 April 2021.

In the version of this Viewpoint article originally published, the author list and affiliations were mistakenly not included; they have now been added to the online versions of the Viewpoint article.

Published online: 14 June 2021

https://doi.org/10.1038/s41558-021-01063-0

(C) Springer Nature Limited 2021 